\title{
Показатели конгруэнтности, подвижности и степени свободы крупных суставов конечностей и позвоночника как ориентиры для проектирования занятий фитнесом с мужчинами 40-55 лет
}

\author{
Кованова C.C. ${ }^{*}$, Cmenaнова O.H. ${ }^{2}$ \\ ${ }^{1}$ Шуйский филиал Ивановского государственного университета \\ 2. Шуя, Россия \\ ORCID: oooo-ooo3-2414-1070, skovanova@yandex.ru* \\ ${ }^{2}$ Московский педагогический государственный университет \\ 2. Москва, Россия \\ ORCID: oooo-ooo2-4114-2801, stepanova.olga.mpgu@gmail.com
}

\begin{abstract}
Аннотация: Самыми частыми посетителями фитнес-центров являются мужчины и женщины зрелого возраста. В зрелом возрасте проявляются первые признаки старения: снижается гормональный фон, появляется лишний вес, соединительная ткань теряет свою эластичность, дают о себе знать первые признаки структурно-функциональных нарушений позвоночника и суставов. Важно не упустить момент начала дегенеративных нарушений, вовремя провести диагностику и построить оздоровительно-кондиционную тренировочную программу занятий с учетом выявленных нарушений. Материалъ. В статье представлены результаты комплексной диагностики конгруэнтности, подвижности и степени свободы крупных суставов и позвоночника мужчин зрелого возраста (4055 лет), занимающихся фитнесом. В обследовании приняли участие 6о мужчин зрелого возраста. Материалы тестирования послужили ориентирами для разработки методики оздоровительно-кондиционной (фитнес-) тренировки мужчин второго периода зрелого возраста со структурно-функциональными нарушениями позвоночника и крупных суставов. Методы исследования. Анализ и обобщение литературных первоисточников по проблеме исследования, анамнез, антропометрические измерения, тестирование, оценка функциональной подвижности коленного и тазобедренного суставов с использованием опросников KOOS и HOOS, математико-статистическая обработка данных методом средних величин. Резулътатъ. Оценена степень свободы, подвижности и мобильности крупных суставов и позвоночника у мужчин 40-55 лет, выявлены структурнофункциональные нарушения опорно-двигательного аппарата испытуемых. Заключение. Результаты исследования выступили ориентирами для определения направленности и выбора содержания оздоровительно-кондиционной (фитнес-) тренировки мужчин второго периода зрелого возраста.

Ключевые слова: мужчины 40-55 лет; степень свободы, конгруэнтность, подвижность и мобильность крупных суставов и позвоночника; фитнес-тестирование; оздоровительнокондиционная (фитнес-) тренировка мужчин второго периода зрелого возраста.
\end{abstract}

Для цитирования: Кованова С.С.*, Степанова О.Н. Показатели конгруэнтности, подвижности и степени свободы крупных суставов конечностей и позвоночника как ориентиры для проектирования занятий фитнесом с мужчинами 40-55 лет. Педагогико-психологические и медико-биологические проблемы физической культуры и спорта. 2020; 15(4): 27-37. DOI: 10.14526/2070-4798-2020-15-427-37

The indices of congruence, mobility and degrees of freedom of large joints of extremities and a spine as reference points for fitness lessons projection in 40-55 year-old men

\author{
Sofiya S. Kovanova ${ }^{1^{*}}$, Olga N. Stepanova ${ }^{2}$ \\ ${ }^{1}$ Shuya branch of Ivanovo State University \\ Shuya, Russia \\ ORCID: oooo-ooo3-2414-107o, skovanova@yandex.ru* \\ ${ }^{2}$ Moscow Pedagogical State University \\ Moscow, Russia
}


ORCID: oOoo-ooo2-4114-2801, stepanova.olga.mpgu@gmail.com

\begin{abstract}
Men and women of middle age are the most frequent visitors of fitness centers. The first signs of aging appear during middle age: hormonal background decreases, excess weight appears, connective tissue loses elasticity, the first signs of spine and joints structural-functional disorders appear. It is important not to miss the moment of degenerative disorders, to realize timely diagnostics and build health-improving conditional training program of lessons, taking into account the revealed disorders. Materials. The article presents the results of a complex diagnostics of congruence, mobility and degrees of freedom of large joints and a spine among men of middle age (40-55 years-old), who go in for fitness. 60 men of middle age took part in the research. The material of testing were the reference points for the methodology creation of health-improving conditional (fitness) training in men of the second period of middle age with structural-functional disorders of spine and large joints. Research methods. Analysis and summarizing literary sources on the research problem, anamnesis, anthropometric measurements, testing, assessment of the knee and hip joints functional mobility using the KOOS and HOOS questionnaires, mathematical and statistical data processing by the method of average values. Results. We estimated the degree of freedom, mobility of large joints and spine among 40-55 year-old men, revealed structural-functional disorders of locomotor apparatus. Conclusion. The results of the research were the reference points for the orientation determination and content choice of health-improving conditional (fitness) training in men of the second period of middle age.

Keywords: 40-55 year-old men; degree of freedom, congruence, flexibility and mobility of large joints and spine; fitness testing; health-improving and conditional (fitness) training for men of the second period of adulthood.
\end{abstract}

For citation: Sofiya S. Kovanova*, Olga N. Stepanova. The indices of congruence, mobility and degrees of freedom of large joints of extremities and a spine as reference points for fitness lessons projection among 40-55 year-old men. Russian Journal of Physical Education and Sport. 2020; 15(4): 27-37. DOI: 10.14526/2070-4798-2020-15-4-27-37

\section{ВВЕДЕНИЕ}

Частыми посетителями фитнес-центров являются мужчины зрелого возраста (4055 лет). Несмотря на то что в этом возрасте у мужчин сохраняется достаточно высокий уровень тренируемости двигательных функций и имеются благоприятные предпосылки для достижения существенных оздоровительных [6, $7,9,10,14]$ и даже спортивных результатов [15, 16], у них проявляются первые признаки старения: снижение гормонального фона $[3,4]$, лишний вес [12], потеря эластичности соединительной ткани [11] , обострение хронических заболеваний вредными привычками [8], дегенеративнодистрофические изменения [17] и, как следствие, структурно-функциональные нарушения позвоночника и суставов $[5,11,14,16,17]$. Это означает, что при построении индивидуальной программы оздоровительно-кондиционной (фитнес-) тренировки мужчин зрелого возраста важно учитывать вид и степень выраженности структурно-функциональных нарушений позвоночника и суставов и в соответствии с этим подбирать и включать в тренировочную программу средства их коррекции и профилактики $[18,19]$.

В этой связи задачами исследования выступили: во-первых, оценка конгруэнтности, подвижности и степени свободы крупных суставов конечностей и позвоночника мужчин второго периода зрелого возраста; во-вторых, разработка рекомендаций по выбору средств оздоровительно-кондиционной (фитнес-) тренировки мужчин 40-55 лет, имеющих различные виды структурно-функциональных нарушений позвоночника и суставов.

\section{МАТЕРИАЛЫ И МЕТОДЫ ИССЛЕДОВАНИЯ}

Оценка конгруэнтности, подвижности и степени свободы крупных суставов конечностей и позвоночника мужчин 40-55 лет производилась с использованием следующих диагностических процедур (тестов и шкал):

- sacral clearing test, faber test, posh test, squish test, alternate gillet test, с помощью 
которых оценивалась стабильность крестцовогоподвздошного отдела позвоночника;

- gaenslen test, lumbar quadrant test, resisted abduction test, fortin's sign, posteroanterior mobility, prone instability test, resisted abduction test (стабильность), standing forward flexion test, посредством которых оценивалась подвижность поясничного отдела позвоночника;

- active sit-up test, extensor endurance test, alternate gillet test, prone instability test, spine rotators and multifidus test, sphinx test - для оценки развитости мышц кора;

- crossed straight leg raise test, slump test, straight leg raise test - на предмет выявления грыж и протрузий;

- gower's sign, prone knee bend test, seated forward flexion test, supine to long sit test, supine to long sit test - с целью выявления искривлений (отклонений от фронтальной оси) позвоночника;

- теста «колено к стене» - для оценки мобильности голеностопного сустава;

- neer's test, hawkin's test, drop arm test, belly press test, lift off test, adduction and external rotation test, jobe test - на предмет оценки подвижности и конгруэнтности плечевого сустава;

- опросной шкалы «The knee injury and osteoarthritis outcome score» (KOOS) - для оценки функциональной подвижности коленного сустава [1];

- опросной шкалы «Hip disability and osteoarthritis outcome score» (HOOS) - для оценки функциональной подвижности тазобедренного Таблица 1 - Показатели телосложения мужчин 40-55 лет, занимающихся в фитнес-клубе «SKFITNESS» (г. Москва) $(\mathrm{n}=60)$

сустава [2].

Для оценки состояния здоровья и телосложения испытуемых были использованы методы анамнеза и антропометрии. Результаты обследования и тестирования обрабатывались методами описательной статистики.

Как видно из набора диагностических процедур, особое внимание в исследовании уделялось оцениванию функциональности поясничного и крестцового отделов позвоночника, а также крупных суставов (тазобедренного, коленного, голеностопного и плечевого) по направлениям: подвижность, функциональность (в повседневной жизни, при занятиях спортом и активном отдыхе), боль (степень выраженности, характер, факторы, провоцирующие болевой синдром), симптомы, наличие травм в прошлом, общее качество жизни.

Исследование проводилось на базе фитнес-клуба «SKFITNESS» (г. Москва). Выборка исследования - 60 мужчин зрелого возраста (40-55 лет), приобретших клубную карту и направленных в центр тестирования указанного фитнес-клуба.

\section{РЕЗУЛЬТАТЫ ИССЛЕДОВАНИЯ И ИХ ОБСУЖДЕНИЕ}

В ходе антропометрических измерений было установлено, что обследуемые имеют гиперстеничный (эндоморфный) тип телосложения и избыточный вес (таблица 1).

\begin{tabular}{|c|c|c|}
\hline No & Показатели & $\bar{X} \pm \boldsymbol{\sigma}$ \\
\hline $\mathbf{\Pi} \mathbf{\Pi}$ & Рост, см & $181,6 \pm 1,5$ \\
\hline 1 & Масса тела, кг & $101,5 \pm 2,65$ \\
\hline 2 & Окружность грудной клетки, см & $110,3 \pm 9,72$ \\
\hline 5 & Окружность запястья & $18,5 \pm 3,25$ \\
\hline 3 &
\end{tabular}

Результаты оценки амплитуды движений и выявления ограничений в подвижности поясничного отдела позвоночного столба, диагностики силы и способности к растяжимости мышц кора (пресса, ягодиц, разгибателей позвоночника, спины) [18] представлены в таблице 2. 
Таблица 2 - Оценка подвижности и стабильности позвоночного столба мужчин 40-55 лет (по результатам тестирования мышц соre) $(\mathrm{n}=60)$

\begin{tabular}{|c|c|}
\hline Наименование теста & $\begin{array}{c}\text { Положительный результат (\% } \\
\text { испытуемых) }\end{array}$ \\
\hline Active sit-up test & 0 \\
\hline Extensor endurance test & 100 \\
\hline Prone instability test & 80 \\
\hline Spine rotators and multifidus test & 16 \\
\hline Sphinx test & 0 \\
\hline Alternate gillet test & 100 \\
\hline
\end{tabular}

Как видно из таблицы 2, в тесте на удержание корпуса в статическом положении «active sit-up test» все 100\% испытуемых продемонстрировали «отрицательный» результат, поскольку никто из них не был в состоянии удержать стабильное положение более 5 секунд без перераспределения нагрузки на поясничный отдел позвоночника. Тест на развитость мышц-разгибателей (экстензоров) позвоночника «Extensor endurance test» выдержали все испытуемые. 80\% испытуемых продемонстрировали «положительный» результат в тесте на удержание корпуса с использованием скамьи «prone instability test», у 20\% была зафиксирована боль в пояснице. Тест на ротацию в поясничном отделе позвоночника «spine rotators and multifidus test» успешно прошли лишь 16\% испытуемых, у 84\% была выявлена асимметрия в движении, неспособность поддерживать таз и статично удерживать нейтральное положение спины

Таблица 3 - Результаты тестирования мужчин 40-55 лет на наличие грыж и протрузий $(\mathrm{n}=28)$

\begin{tabular}{|c|c|}
\hline Наименование теста & $\begin{array}{c}\text { Положительный результат (\% } \\
\text { испытуемых) }\end{array}$ \\
\hline Crossed straight leg raise test & 92 \\
\hline Slump test & 46 \\
\hline Straight leg raise test & 23 \\
\hline
\end{tabular}

В тесте «crossed straight leg raise test», который проводился в положении лежа на спине, у 92\% обследуемых боль возникала при диапазоне $74-84^{\circ}$ (при «отрицательном» значении от $90^{\circ}$ ), что свидетельствовало о «положительном» результате тестирования с поднятой рукой; отведение руки в сторону вызывало у них дисбаланс, положение корпуса стабилизировалось только через 2 секунды. В тесте «sphinx test», проводимом с целью оценки асимметрии тазобедренного сустава и ягодиц при напряжении поясницы в положении лежа, у всех испытуемых при напряжении была выявлена асимметрия около 3-6을 нейтрали. «Alternate gillet test» (при норме - отсутствие движений) показал наличие у испытуемых компенсаторных реакций при подъеме ноги из положения стоя, хотя данный тест все испытуемые прошли с положительным результатом.

Тесты на наличие грыж и протрузий (таблица 3) проводились с теми испытуемыми, у которых в анамнезе не было упоминаний о наличии пластических нарушений в позвоночном столбе (таковых насчитывалось 28 человек). Если в анамнезе присутствовало упоминание о травме без дальнейшей диагностики, тесты не проводились. 
успешно прошли всего 23\% обследуемых; у остальных наблюдалось усиление боли в спине при сгибании в тазобедренном суставе до угла в 30-35 (при норме $40^{\circ}$ и выше).

Тестирование показало, что практически всех испытуемых объединяет боль, вызванная наличием грыжи или протрузии в поясничном отделе позвоночного столба (92\%), и лишь у $4 \%$ испытуемых обнаружились (в анамнезе) протрузии в шейном отделе позвоночника. После положительного реагирования на тест (то есть грыжа, протрузия выявлена), испытуемому рекомендовалось пройти обследование с использованием магнитно-резонансной томографии и проконсультироваться с врачомхирургом перед началом занятий фитнесом.

Тест «gaenslen test», проводимый при флексии бедра (таблица 4), показал, что у 26\% испытуемых возникала боль в подвздошнопоясничной мышце; «lumbar quadrant test»; ограничение движений в боковых наклонах зафиксировано у 46\% испытуемых.

Таблица 4 - Результаты диагностики подвижности поясничного отдела позвоночника мужчин 4055 лет $(\mathrm{n}=60)$

\begin{tabular}{|c|c|}
\hline Наименование теста & $\begin{array}{c}\text { Положительный результат (\% } \\
\text { испытуемых) }\end{array}$ \\
\hline Gaenslen test & 26 \\
\hline Lumbar quadrant test & 23 \\
\hline Resisted abduction test & 100 \\
\hline Fortin's sign & 100 \\
\hline
\end{tabular}

«Resisted abduction test», предназначенный для оценки силы приводящих мышц, средней и малой ягодичных мышц в статическом режиме (стабильность положения) и выполняемый из положения лежа, был положителен у 23\% обследованных. «Fortin's sign», характеризующий наличие локализованного очага боли в поясничноподвздошной фасции, был положительным у всех испытуемых (вследствие наличия грыжи в поясничном отделе позвоночника, усугубленной нахождением испытуемых большую часть времени в положении сидя). «Standing forward flexion test», предназначенный для оценки гипомобильности позвоночника (при наклоне вперед), был положителен у всех испытуемых.

При проведении «posh test» (скручивание, наружняя ротация) и «faber test» у обследованных острой боли в крестцовогоподвздошном отделе не возникало, что свидетельствует о стабильности указанного отдела позвоночника (таблица 5).

Таблица 5 - Оценка стабильности крестцового отдела позвоночника мужчин 40-55 лет (n=60)

\begin{tabular}{|c|c|}
\hline Наименование теста & $\begin{array}{c}\text { Положительный результат (\% } \\
\text { испытуемых) }\end{array}$ \\
\hline Faber test & 0 \\
\hline Posh test & $100 \%$ \\
\hline Alternate gillet test & 0 \\
\hline
\end{tabular}

«Alternate gillet test» проводился в повседневной и спортивной жизни по в комплексе с оценкой мышц core, его результаты свидетельствуют о неравномерном распределении нагрузки на мышцы спины.

Рассмотрим результаты оценки функциональности коленного и тазобедренного суставов обследованных мужчин 40-55 лет каждому из направлений: боль, симптомы, ограничение активности в повседневной жизни, функционирование суставов при занятиях спортом и активном отдыхе, общее качество жизни по 10о-балльной опросной шкале «Тhe knee injury and osteoarthritis outcome score» 
(KOOS) и «Hip Disability and Osteoarthritis Outcome Score» (HOOS) [1, 2].

Что касается симптоматики, то испытуемые отмечали умеренно-постоянный уровень боли в покое, положениях сидя и лежа и при выполнении простых двигательных действий. Усиление боли отмечалось при спусках, подъемах по лестнице, приседаниях на носках, при полном сгибании коленного сустава, при резких движениях в сторону, выпадах, а также при опорной нагрузке (прыжках, беге). Средний балл был равен 36. Сложно-координационные упражнения (при полном сгибании коленного сустава), прыжки и циклические упражнения (бег, езда на велосипеде) выполнялись испытуемыми с трудом и сопровождались сильной и острой болью в коленном суставе. Качество жизни испытуемые оценили как низкое (в среднем 18 баллов из 100 возможных) в силу наличия постоянных (ежедневных) болевых ощущений, беспокойства, ограничения или отказа от выполнения некоторых двигательных действий, неуверенности в возможности выполнить то или иное двигательное действие, что вносило значительные ограничения в повседневную двигательную активность обследуемых.

Помимо определения боли, симптомов, сложности выполнения бытовых действий, активности и влияния травм колена на качество жизни, нами была проведена диагностика силы активного аппарата коленного сустава - мышц сгибателей и разгибателей бедра, которые производились по тестам «leg extension» и «leg flexion» с использованием тренажеров блочного типа. Средний вес при сгибании бедра составил 40 килограммов при выполнении
4-5 повторений, что свидетельствует о слабой и средней силе мышц-сгибателей (двуглавая мышца бедра, полуперепончатая, полусухожильная мышцы). Отметим, что тестирование проводилось на «больной ноге» с использованием блочного тренажера «Кроссовер» (двойная регулируемая тяга), где средний вес тяги составил 30 килограммов при количестве повторений, равном 6. При выполнении разгибания средний вес тяги составил 30-35 кг при 5 повторениях, что также свидетельствует о слабой функциональности четырехглавой мышцы бедра.

Оценка подвижности (мобильности) голеностопного сустава в тесте «колено к стене» показало «хорошее» значение данного показателя у всех испытуемых (23,0 $\pm 3,4$ см).

Диагностика нарушений акромиальноключичного сочленения [5, 13, 15] по тестам «neer's test» и «hawkin's test» из положения сидя и стоя продемонстрировала положительный результат. Боль и «хруст в суставе» возникали как при внутреннем вращении плеча, так и в переднелатеральной части плеча. «Drop arm test» показал, что у испытуемых не обнаружено проблем с вращательной манжетой плеча. Все испытуемые могли выполнять плавные движения и были способны длительно удерживать статическое напряжение без возникновения боли.

Тесты на оценку сухожилий подлопаточной мышцы «lift off test» и «jobe test», сухожилий надостной мышцы «adduction and external rotation test» [19] показали отрицательный результат, что свидетельствует об отсутствии микротравм в сухожилиях.

Таблица 6 - Оценка конгруэнтности плечевого сустава мужчин 40-55 лет (n=60)

\begin{tabular}{|c|c|}
\hline Наименование теста & $\begin{array}{c}\text { Положительный результат (\% } \\
\text { испытуемых) }\end{array}$ \\
\hline Neer's test & 100 \\
\hline Hawkin's test & 100 \\
\hline Drop arm test & 0 \\
\hline Belly press test & 0 \\
\hline Lift off test & 0 \\
\hline Adduction and external rotation test & 0 \\
\hline Jobe test & 0 \\
\hline
\end{tabular}


Результаты диагностики показали, что нестабильность плечевого сустава у данной возрастной группы вызвана большей частью неразвитостью силы мышц верхнего плечевого пояса.

Отталкиваясь от данных анамнеза и тестирования, нами были выведены типологические группы мужчин 40-55 лет, имеющих сходные структурно-функциональные нарушения позвоночного столба и суставов:

- группа A - испытуемые с нарушениями позвоночного столба (грыжи, протрузии, искривление, сколиозы I степени, остеохондрозы);

- группа К - испытуемые с нарушениями и заболеваниями коленных суставов (частичное или полное повреждение менисков в стадии ремиссии, частичный разрыв связок и сухожилий);

- группа C - испытуемые с нарушением свода стопы (плоскостопие: продольное и поперечное, гипомобильная стопа);

- группа П - испытуемые с нарушением подвижности плечевого сустава;

- группа T - испытуемые с нарушением подвижности тазобедренного сустава.

Для каждой из групп была разработана своя программа оздоровительно-кондиционной (фитнес-) тренировки. В таблице 7 представлены рекомендуемые средства фитнес-тренировки, режимы ихприменения, атакжедополнительные средства оздоровления (массаж, гидро- и термопроцедуры, фармакологические средства).

Таблица 7 - Рекомендуемые средства оздоровительно-кондиционной (фитнес-) тренировки мужчин 40-55 лет со структурно-функциональными нарушениями позвоночника и суставов

\begin{tabular}{|c|c|c|c|}
\hline $\begin{array}{c}\text { Структурно- } \\
\text { функциональные } \\
\text { нарушения } \\
\text { позвоночного } \\
\text { столба и суставов }\end{array}$ & $\begin{array}{c}\text { Рекомендуемые средства } \\
\text { фитнес-тренировки }\end{array}$ & $\begin{array}{c}\text { Соотношение } \\
\text { применяемых } \\
\text { средств фитнес- } \\
\text { тренировки }\end{array}$ & $\begin{array}{c}\text { Дополнительные } \\
\text { средства } \\
\text { оздоровления }\end{array}$ \\
\hline $\begin{array}{l}\text { Нарушения } \\
\text { позвоночного столба } \\
\text { (грыжи, протрузии, } \\
\text { искривление, } \\
\text { сколиозы І степени, } \\
\text { остеохондрозы) (группа } \\
\text { А) }\end{array}$ & $\begin{array}{l}\text { Изометрические, } \\
\text { изотонические упражнения } \\
\text { на локальные мышечные } \\
\text { группы; функциональные } \\
\text { упражнения, направленные } \\
\text { на увеличение подвижности } \\
\text { позвоночного столба, } \\
\text { касательно оси расположения } \\
\text { болевого синдрома; } \\
\text { упражнения с использованием } \\
\text { неустойчивых опор; подвесной } \\
\text { тренинг; статические } \\
\text { и статодинамические } \\
\text { упражнения; упражнения с } \\
\text { сопротивлением; упражнения } \\
\text { с весом собственного тела; } \\
\text { упражнения с предметами; } \\
\text { точностно- координационные } \\
\text { упражнения; идеомоторные } \\
\text { упражнения; упражнения на } \\
\text { мышцы кора; «кифозные» или } \\
\text { кифозирующие упражнения. }\end{array}$ & $\begin{array}{l}\text { Изометрические, } \\
\text { изотонические } \\
\text { упражнения -10- } \\
15 \% . \\
\text { Локальные } \\
\text { упражнения -20- } \\
40 \% . \\
\text { Упражнения с } \\
\text { оборудованием, } \\
\text { на неустойчивых } \\
\text { опорах - 40-55\%. }\end{array}$ & $\begin{array}{l}\text { Массаж, гидропроцедуры } \\
\text { (солевые ванны), } \\
\text { кинезиотейпирование, } \\
\text { миофасциальный релиз, } \\
\text { оздоровительное питание, } \\
\text { витаминно-минеральные } \\
\text { комплексы. }\end{array}$ \\
\hline
\end{tabular}




\begin{tabular}{|c|c|c|c|}
\hline $\begin{array}{c}\text { Структурно- } \\
\text { функциональные } \\
\text { нарушения } \\
\text { позвоночного } \\
\text { столба и суставов }\end{array}$ & $\begin{array}{c}\text { Рекомендуемые средства } \\
\text { фитнес-тренировки }\end{array}$ & $\begin{array}{c}\text { Соотношение } \\
\text { применяемых } \\
\text { средств фитнес- } \\
\text { тренировки }\end{array}$ & $\begin{array}{c}\text { Дополнительные } \\
\text { средства } \\
\text { оздоровления }\end{array}$ \\
\hline $\begin{array}{l}\text { Нарушения и } \\
\text { заболевания } \\
\text { коленных суставов } \\
\text { (частичное или полное } \\
\text { повреждение менисков } \\
\text { в стадии ремиссии, } \\
\text { частичный разрыв } \\
\text { связок и сухожилий) } \\
\text { (группа К) }\end{array}$ & $\begin{array}{l}\text { Растяжка и стретчинг основных } \\
\text { мышц- стабилизаторов } \\
\text { (квадрицепцы, бицепсы } \\
\text { бедер, икроножные мышцы, } \\
\text { камбалавидные мышцы); } \\
\text { упражнения на сопротивление; } \\
\text { подвесной тренинг; } \\
\text { упражнения на укрепление } \\
\text { мышц-стабилизаторов; } \\
\text { функциональные балансовые } \\
\text { упражнения; упражнения на } \\
\text { неустойчивых опорах; тяговые } \\
\text { и резистивные упражнения. } \\
\text { С осторожностью и по } \\
\text { специальной программе } \\
\text { разрешается использовать } \\
\text { вибрационный тренинг на } \\
\text { платформе. }\end{array}$ & $\begin{array}{l}\text { Стретчинг } \\
\text { (растягивание) } \\
\text { основных мышц- } \\
\text { стабилизаторов - } \\
20-25 \% . \\
\text { Упражнения на } \\
\text { сопротивление - 10- } \\
\text { 15\%. } \\
\text { Упражнения на } \\
\text { неустойчивых } \\
\text { опорах и с } \\
\text { использованием } \\
\text { дополнительного } \\
\text { оборудования - 50- } \\
\text { 55\%. }\end{array}$ & $\begin{array}{l}\text { Кинезиотейпирование, } \\
\text { миофасциальный релиз, } \\
\text { миостимуляция, } \\
\text { магнитная терапия, } \\
\text { вибрационная платформа, } \\
\text { оздоровительное питание, } \\
\text { витаминно-минеральные } \\
\text { комплексы. }\end{array}$ \\
\hline $\begin{array}{l}\text { Нарушение свода } \\
\text { стопы (продольное } \\
\text { и поперечное } \\
\text { плоскостопие, } \\
\text { гипомобильная стопа) } \\
\text { (группа С) }\end{array}$ & $\begin{array}{l}\text { Упражнения, увеличивающие } \\
\text { пространство между } \\
\text { суставными поверхностями } \\
\text { костей стопы; упражнения на } \\
\text { гибкость стопы; упражнения } \\
\text { в перспективах и проекциях } \\
\text { физиологических движений; } \\
\text { упражнения локального } \\
\text { характера, учитывающие } \\
\text { компенсацию в движениях; } \\
\text { работа с пальцами стоп; } \\
\text { идеомоторные упражнения; } \\
\text { упражнения для голени и стопы } \\
\text { (подъёмы на носки, пятки); } \\
\text { упражнения на нестабильных } \\
\text { поверхностях и неустойчивых } \\
\text { опорах }\end{array}$ & $\begin{array}{l}\text { Упражнения на } \\
\text { гибкость стопы - } \\
\text { 10-15. } \\
\text { Упражнения } \\
\text { на увеличение } \\
\text { пространства } \\
\text { между суставными } \\
\text { поверхностями - } \\
\text { 35\%. } \\
\text { Упражнения для } \\
\text { голени и стопы -20- } \\
\text { 25\%. } \\
\text { Упражнения на } \\
\text { нестабильных } \\
\text { поверхностях и } \\
\text { опорах - 15\%. }\end{array}$ & $\begin{array}{l}\text { Миофасциальный } \\
\text { релиз, массаж, } \\
\text { кинезиотейпирование, } \\
\text { самомассаж, ультразвук, } \\
\text { криотерапия, } \\
\text { миостимуляция, } \\
\text { оздоровительное питание. }\end{array}$ \\
\hline
\end{tabular}




\begin{tabular}{|c|c|c|c|}
\hline $\begin{array}{c}\text { Структурно- } \\
\text { функциональные } \\
\text { нарушения } \\
\text { позвоночного } \\
\text { столба и суставов }\end{array}$ & $\begin{array}{c}\text { Рекомендуемые средства } \\
\text { фитнес-тренировки }\end{array}$ & $\begin{array}{c}\text { Соотношение } \\
\text { применяемых } \\
\text { средств фитнес- } \\
\text { тренировки }\end{array}$ & $\begin{array}{c}\text { Дополнительные } \\
\text { средства } \\
\text { оздоровления }\end{array}$ \\
\hline $\begin{array}{l}\text { Нарушение } \\
\text { подвижности плечевого } \\
\text { сустава (группа П) }\end{array}$ & $\begin{array}{l}\text { Упражнения на мобилизацию } \\
\text { шейного отдела позвоночника; } \\
\text { упражнения на мобилизацию } \\
\text { лопатки; упражнения на } \\
\text { удержание и расслабление при } \\
\text { активной и пассивной ротации } \\
\text { плеча; расслабление и релиз } \\
\text { широчайшей мышцы спины и } \\
\text { малой грудной мышцы. }\end{array}$ & $\begin{array}{l}\text { Мобилизация } \\
\text { шейного отдела - } \\
\text { 15-25\%. } \\
\text { Релиз, упражнения } \\
\text { на удержание и } \\
\text { расслабление - 20- } \\
25 \% . \\
\text { Упражнения на } \\
\text { расслабление } \\
\text { широчайших мышц } \\
\text { спины - 25-35\%. }\end{array}$ & $\begin{array}{l}\text { Кинезиотейпирование, } \\
\text { миофасциальный } \\
\text { релиз, массаж, } \\
\text { прием нестероидных } \\
\text { противовоспалительных } \\
\text { препаратов. применение } \\
\text { противовоспалительных } \\
\text { мазей, массаж, } \\
\text { гидропроцедуры, } \\
\text { оздоровительное питание. }\end{array}$ \\
\hline $\begin{array}{l}\text { Нарушение } \\
\text { подвижности } \\
\text { тазобедренного сустава } \\
\text { (группа T) }\end{array}$ & $\begin{array}{l}\text { Упражнения для укрепления } \\
\text { и улучшения трофики мышц- } \\
\text { стабилизаторов тазобедренных } \\
\text { суставов (мышцы тазового } \\
\text { дна, ягодичные, приводящие, } \\
\text { сгибатели и разгибатели бедра); } \\
\text { полуприседания с опорой; } \\
\text { упражнения на сгибание } \\
\text { и разгибание, отведение } \\
\text { и приведение бедра на } \\
\text { тренажерах и без отягощений } \\
\text { (в том числе в статическом } \\
\text { напряжении указанных мышц). }\end{array}$ & $\begin{array}{l}\text { Упражнения, } \\
\text { улучшающие } \\
\text { трофику мышц- } \\
\text { стабилизаторов - } \\
\text { 25-35\%. } \\
\text { Упражнения } \\
\text { на сгибание и } \\
\text { разгибание, } \\
\text { отведение и } \\
\text { приведение бедра - } \\
45 \% . \\
\text { Статические } \\
\text { упражнения -10- } \\
\text { 15\%. }\end{array}$ & $\begin{array}{l}\text { Кинезиотейпирование, } \\
\text { массаж, магнитотерапия, } \\
\text { мази, миофасциальный } \\
\text { релиз, приём витаминов } \\
\text { и микроэлементов } \\
\text { в комплексах, } \\
\text { оздоровительное питание. }\end{array}$ \\
\hline
\end{tabular}


Материалы таблицы 7 могут служить основой для разработки индивидуальных программ оздоровительно-кондиционной (фитнес-) тренировки мужчин зрелого возраста, максимально учитывающих вид и степень выраженности структурно-функциональных нарушений позвоночника и суставов.

\section{ЗАКЛЮЧЕНИЕ}

Предлагаемая схема оздоровительнокондиционной (фитнес-) тренировки успешно используется в фитнес-клубе «SKFITNESS» г. Москвы с 2017 года. Ее применение способствует решению задач: нормализации гомеостаза, совершенствования параметров телосложения, улучшения эластичности и растяжимости соединительной ткани, улучшения подвижности, мобильности и конгруэнтности крупных суставов и позвоночника, купирования хронических заболеваний и дегенеративно-дистрофических изменений позвоночника и крупных суставов верхних и нижних конечностей, снижения выраженности болевого синдрома, повышения уровня физической подготовленности, улучшения психоэмоционального статуса и повышения индекса качества жизни мужчин 40-55 лет.

\section{СПИСОК ЛИТЕРАТУРЫ}

1. Бирюкова Е.В., Гурьев В.В., Зоря В.И, Прокопенко Р.А., Фролов А.А. Биомеханический анализ показателей движений в тазобедренном, коленном и голеностопном суставах у больных c коксартрозом как метод функциональной диагностики. Бюллетень ВСНЦ со РАМН. 2010; 6(76); 1: 21-29.

2. Бараненков А.А., Голозубов О.М., Голубев, В.Г. Голубев Г.Ш., Жданов В.Г. Региональная адаптация шкалы оценки исходов повреждений и заболеваний коленного сустава KOOS. Травматология и ортопедия. 2007; 1(43): 26-30.

3. Гаврильев С.И., Черкашин И.А. Контроль физической подготовленности мужчин второго зрелого возраста в процессе оздоровительных занятий. Теория и практика физической культуры. 2020; 10ю URL: http:// www.teoriya.ru/ru/node/12681.

4. Гаврильев С.И., Черкашин И.А. Изменение физической подготовленности мужчин второго зрелого возраста, посещающих занятия оздоровительной направленности с элементами тенниса. Ученые записки университета имени П.Ф. Лесгафта. 2020; 7(185): 65-70. DOI: 10.34835/issn.23081961.2020.7.p65-70

5. Гершбург М.И., Казубская Т.А. Программа реабилитации спортсменов после оперативного лечения хронической нестабильности плечевого сустава. Лечебная Физкультура и спортивная медицина. 2015; 2 (128): 4-10.

6. Евграфов И.Е., Кузнецова 3.М. Физическое состояние и здоровье мужчин второго зрелого возраста, занимающихся по программе физкультурно-оздоровительной направленности. Теория и практика физической культуры. 2010; 3: 90-92.

7. Кривицкая, Е.И. Каченкова Е.C. Проблема снижения физической работоспособности мужчин 50-60 лет и ее коррекция средствами оздоровительной тренировки. Ученые записки университета имени П.Ф. Лесгафта. 2017; 9 (151): 118-124.

8. Каченкова Е.С., Кривицкая Е.И. Оптимизация функции внешнего дыхания и общей работоспособности мужчин 50-60 лет средствами оздоровительной тренировки. Ученые записки университета имени П.Ф. Лесгафта. 2020; 3(181): 200-204. DOI: 10.34835/ issn.2308-1961.2020.3.p200-204

9. Лутченко И.Г., Перевозникова И.И., Высоцкий Ю.М. Научно-теоретические аспекты совершенствования онтокинезиологического потенциала человека. Теория u практика физической культуры. 2015; 3: 61.

10. Малыгина И.А. Влияние методики оздоровительной двигательной активности на физическое состояние лиц второго периода зрелого возраста. Физическая культура, спорт - наука и практика. 2019; (3): 58-63.

11. Пасмурова Л.Э. Современные проблемы здоровья человека. Педагогикопсихологические и медико-биологические проблемы физической культуры и спорта. 2008; 3(3): 104-110.

12. Разина А.О., Руденко С.Д., Ачкасов Е.Е. Роль физической реабилитации в комплексном лечении ожирения и коррекции избыточной массы тела. Вестник Всероссийского общества специалистов по медико-социальной экспертизе, реабилитации и реабилитационной индустрии. 2015; 4: 93101.

13. Сячин В.Д., Новикова Т.В. Средства и методы физической реабилитации спортсменов при оперативном лечении повреждений плечевого сустава. Ученые записки 
университета имени П.Ф. Лесгафта. 2019; 1 (167): 286-289.

14. Стафеева А.В., Дерябина А.Л. Эффективность физкультурно-оздоровительных занятий силовым фитнесом с мужчинами зрелого возраста. Успехи современной науки и образования. 2016; 1 (12): 209-212.

15. Савин C.В., Степанова О.Н., Соколова В.С., Николаев И.В. Оздоровительная тренировка лиц зрелого возраста: направленность, содержание, методики. М.: МПГУ, 2017.

16. Степанова О.Н., Савин С.В. Направленность, содержание и методика комплексной фитнес-тренировки мужчин первого периода зрелого возраста. Педагогикопсихологические и медико-биологические проблемы физической культуры и спорта.
2020; 15(1): 96-105. DOI: 10.14526/2070-47982020-15-1-96-105.

17. Скворцов Д.В., Диагностика патологий движений в отечественной неврологии. Бюллетень медицинских интернет-конференций. 2012; 2(9): 651.

18. Reiman M.P., Goode A.P., Hegedus E.J., Cook C.E., Wright A.A. Diagnostic accuracy of clinical tests of the hip: a systematic review with meta-analysis. Br J Sports Med. 2013; Sep; 47 (14): 893-902. DOI: 10.1136/bjsports-2012-091035

19. Ślęzak M., Lubiatowski P., Lubiatowski B., Łepski M., Imirowicz A., Romanowski L. Polish cultural adaptation of general shoulder assessment scores in use for painful shoulder: ASES, UCLA, Constant Score, SST (Part I). Preliminary study. Issue Rehabil. Orthop. Neurophysiol. Sport Promot. 2016; 17, 7-27.

\section{Статья поступила в редакцию: 06.10.2020}

Кованова София Сергеевна - аспирант, Шуйский филиал Ивановского государственного университета, 1559o8, Россия, Ивановская область, г. Шуя, ул. Кооперативная, дом 24, е-таil: skovanova@yandex.ru

Степанова Ольга Николаевна - доктор педагогических наук, профессор, Московский педагогический государственный университет, 119571, Россия, г. Москва, проспект Вернадского, дом 88, e-mail: stepanova.olga.mpgu@gmail.com, stepanova.olga.75@gmail.com 